\title{
Consideraciones en torno a la viabilidad de implementación del voto electrónico en México
}

\section{Carla A. Humphrey Jordan*}

\section{Sumario:}

I. Introducción

II. Voto electrónico. Concepto, características y modalidades

III. Experiencia internacional en materia de voto electrónico

IV. Experiencia mexicana en materia de voto electrónico

V. ¿Es viable la regulación e implementación del voto electrónico en México?

VI. Conclusiones

* Consejera electoral en el Instituto Electoral del Distrito Federal.

D. R. () 2013. Universidad Nacional Autónoma de México-Instituto de Investigaciones Jurídicas. 


\section{Introducción}

En los últimos años se ha debatido desde distintos ámbitos la posibilidad de diseñar, crear e implementar políticas o programas que se traduzcan en la reducción de los costos de los procesos electorales en todo el país. Algunas propuestas han versado sobre la reducción de prerrogativas de los partidos políticos y reducción de las campañas electorales - esto último incorporado ya a la legislación electoral federal, mediante la reforma política de 2007-2008 y fue retomado, al menos en lo esencial, por algunas entidades federativas-. Otras propuestas han versado en analizar la posibilidad de generar procedimientos conforme a los cuales resulte posible reducir el costo de la logística electoral propiamente dicha y, específicamente, de los mecanismos actualmente vigentes para recabar el voto y llevar a cabo el escrutinio y cómputo de los mismos, sin comprometer las cualidades del voto: universal, libre, secreto, directo; ni la observancia de los principios rectores del ejercicio de la función electoral: certeza, legalidad, objetividad, así como la transparencia.

A propósito de lo anterior, de manera reciente han cobrado relevancia las propuestas que han surgido en distintos contextos y ámbitos en el sentido de generar un procedimiento que permita recabar el voto de los ciudadanos a través de cualesquiera de los dispositivos o mecanismos que ofrecen las tecnologías de la información y la comunicación (TIC's), habida cuenta los beneficios y ventajas que el uso de la tecnología puede aportar al sistema político electoral mexicano, considerando que otros países ya han tenido experiencias exitosas al respecto.

No pasa desapercibido, sin embargo, que adoptar un programa o política bajo el solo argumento de que éste resultó exitoso en otro lugar es insuficiente para que resulte definitorio de alguna política en el país, de manera que se pone en evidencia la necesidad de llevar a cabo un análisis exhaustivo y pormenorizado del programa a implementar en cuanto a sus características, costos, modalidades; asimismo, determinar qué necesidad del país se pretende atender con el mismo; cuáles serían los efectos, tanto negativos como positivos con su implementación; entre otros rubros.

De acuerdo con lo expuesto en los párrafos precedentes, y a efecto de contribuir al debate existente sobre la conveniencia o viabilidad para el país de adoptar mecanismos o procedimientos inherentes a las 
TIC’s para recabar la votación y llevar a cabo el escrutinio y cómputo correspondiente, propongo abordar en este texto cuatro apartados.

En el primero de ellos, se ofrece una definición teórica de voto electrónico y se describen las modalidades bajo las cuales el mismo puede llevarse a cabo. En el segundo apartado, se presenta un análisis comparado respecto de la experiencia de otros países que han adoptado esta modalidad de votación, para qué tipos de elección, así como los resultados que han obtenido. Por su parte, el tercer apartado, constituye un análisis del caso mexicano, específicamente la experiencia que ha tenido con la aplicación de las nuevas TIC’s en el ámbito electoral, los resultados obtenidos y un breve diagnóstico sobre la viabilidad o conveniencia de que el voto electrónico, bajo cualesquiera de sus modalidades, pueda implementarse para las distintas elecciones que se llevan a cabo en el país, haciendo un balance puntual sobre las ventajas y desventajas que se advierten sobre el tema. Finalmente, el cuarto apartado, pretende dar respuesta a la pregunta respecto a la conveniencia o viabilidad de implementar el voto electrónico para el país, en qué sentido debería emitirse la regulación respectiva, presentando algunas propuestas que, eventualmente, debieran atender las iniciativas legislativas que se presentaran en torno al tema.

\section{Voto electrónico. \\ Concepto, características y modalidades}

Previo a la definición de voto electrónico propiamente dicha, es importante señalar, siguiendo a Fernando Tuesta, que este concepto se circunscribe en la categoría de automatización de los procesos electorales, la cual "hace referencia a la aplicación de tecnología de procesamiento automático de datos —en sustitución del manual-con el propósito de garantizar la transparencia de las elecciones y acelerar aquellos procesos en que se manejan grandes volúmenes de datos".

En efecto, si lo que se pretende con la implementación de esta modalidad de voto es aprovechar las ventajas que ofrecen las nuevas

1 Tuesta Soldevilla, Fernando, "El voto electrónico", en Nohlen, Dieter et al. (comps.), Tratado de derecho electoral comparado de América Latina, 2a. ed., México, Fondo de Cultura Económica, 2007, p. 952. 
TIC's, es inconcuso que el ejercicio del sufragio forma parte de un proceso amplio e interconectado que tendrá como resultado y efecto que el ciudadano pueda ejercer su voto, que éste sea recabado por la autoridad y se haga el escrutinio y cómputo correspondiente, con total apego a la legalidad y con absoluta transparencia, de manera que los ciudadanos cuenten con la convicción de que el resultado electoral es la manifestación de la voluntad popular. Visto así, es evidente que el voto es un acto que se encuentra circunscrito en un proceso más amplio y complejo, orientado a arrojar un resultado con efectos jurídicos, políticos y sociales, en la medida en que, con la decisión adoptada por la mayoría, se integrarán los órganos de gobierno y representación previstos en la Constitución y las leyes.

Por otra parte, es de señalarse que las TIC’s consisten, según lo señalan los especialistas del tema, en:

Todos aquellos elementos y técnicas utilizadas en el tratamiento y transmisión de información, principalmente de informática, internet y telecomunicaciones... El uso de las mismas entre los habitantes de una población, ayuda a disminuir en un momento determinado la brecha digital existente en dicha localidad, ya que aumenta el conglomerado de usuarios que utilizan dichas tecnologías como medio tecnológico para el desarrollo de sus actividades. Se trata, en suma, de aquellas herramientas y métodos empleados para recabar, retener, manipular o distribuir información. Las tecnologías de la información se encuentran generalmente asociadas con las computadoras y otras técnicas afines aplicadas a la toma de decisiones. $^{2}$

Una vez precisado lo anterior, en términos de lo expuesto por Tuesta:

Se entenderá como voto electrónico aquel que se ejecuta sirviéndose de algún dispositivo electrónico y que se realiza en forma automática en una urna electrónica o en una PC (personal computer o computadora personal). En una terminal se presentan todas las opciones en competencia (partidos políticos o candidaturas), permitiendo la selección inmediata.

2 Cfr. Góngora Cuevas, Genny E., “Tecnología de la información como herramienta para aumentar la productividad de una empresa”, en http://www.tuobra.unam.mx/publicadas/040702105342-_191_Qu.html, consultada el 21 de septiembre de 2012. 
De la misma manera, el conteo de votos es inmediato, posibilitando el escrutinio y entrega de resultados en corto tiempo. ${ }^{3}$

Por otra parte, de acuerdo con ACE Project, portal especializado en el estudio de sistemas electorales de más de 200 países en el mundo, se define el voto electrónico, también denominado e-voting, como "la opción de utilizar medios electrónicos para votar en los referendos y las elecciones". ${ }^{4}$

Como se puede advertir de las definiciones anteriores, el voto electrónico consistirá, pues, en el uso de medios tecnológicos para el ejercicio del sufragio por parte de los ciudadanos, sin que se comprometan en modo alguno las cualidades y características del voto propiamente dicho, ni del proceso electoral en su conjunto.

De acuerdo a lo expuesto, no debe perderse de vista que, con independencia del uso de recursos tecnológicos para recabar la votación, ésta debe contar con las mismas características que se le reconocen al voto emitido por medios tradicionales: universal, libre, secreto y directo:

- Universal, porque el derecho al voto es inmanente a todos los ciudadanos, sin más restricción que cumplir las condiciones que establece el artículo 34 constitucional: contar con 18 años cumplidos y tener un modo honesto de vivir.

- Libre, porque el ciudadano vota por la opción de su preferencia de manera consciente e informada, sin que persona alguna pueda ejercer presión o coacción sobre su voluntad o condicionarle acceso a beneficios o programas públicos a cambio de votar a favor de determinada opción política.

- Secreto, porque el ciudadano emite su voto en privado, y ninguna persona puede requerirle información sobre el sentido del mismo. De acuerdo con organismos e instituciones, como el Instituto para la Democracia y la Asistencia Electoral (IDEA), en el caso de la votación electrónica este es uno de los principales retos: salvaguardar la secrecía del voto, evitando cualquier vínculo entre

Tuesta, op. cit., p. 954.

4 Portal electrónico de ACE Project http://aceproject.org/ace-es/focus/fo_e-voting/ fo_e-voting-what-is-e-voting, consultada el 21 de septiembre de 2012. 
el ciudadano y el voto emitido; es decir, que no exista manera de conocer el sentido del voto emitido por los ciudadanos. ${ }^{5}$

- Directo, porque el ciudadano acude a votar personalmente; el sistema político electoral mexicano no permite que el derecho de un ciudadano a votar sea ejercido por otra persona. Esta es una de las razones que da sustento a la credencial para votar con fotografía, que otorga absoluta certeza de que la persona que acude a emitir el voto es, efectivamente, el titular del derecho.

Pero además de las características anteriores, existen otros valores y principios que también se tutelan en el ejercicio del voto, como la transparencia. En efecto, es criterio reiterado de la Sala Superior del Tribunal Electoral del Poder Judicial de la Federación que si bien la transparencia no es un derecho político electoral propiamente dicho, como el voto, sí es un presupuesto para el ejercicio de los mismos, de manera que el ciudadano debe contar con información completa, veraz y oportuna de cada una de las distintas opciones políticas a efecto de que pueda emitir su voto $y$, eventualmente, poder ejercer otros derechos políticos, como el de afiliarse a alguna fuerza política; contender por algún cargo directivo al interior de la misma; o, incluso, ser postulado a un cargo de elección popular. ${ }^{6}$

Adicionalmente, desde la perspectiva de la implementación del voto a través de dispositivos electrónicos, la transparencia también implica que los ciudadanos deben contar con información plena, veraz, oportuna de que el proceso electoral y, específicamente, la votación, se han desarrollado con estricto apego a la legalidad, conocer el funcionamiento del dispositivo y de los procedimientos para el ejercicio del voto, así como contar con la convicción de que los resultados que se obtengan serán única y estrictamente el reflejo de la voluntad popular.

A mayor abundamiento, existen autores que reconocen en el voto electrónico un amplio catálogo de atributos y características que, a su

5 Cfr. International IDEA, Introducing Electronic Voting: Essential considerations, Estocolmo, IDEA, 2011, p. 7.

6 México, Tribunal Electoral del Poder Judicial de la Federación, “Zárate Vite, Jorge Arturo vs. Comisión del Consejo en materia de Transparencia y Acceso a la Información del Consejo General del Instituto Federal Electoral, Juicio para la protección de los derechos político electorales del ciudadano", exp. núm. SUP-JDC-041/2004, 25 de junio de 2004, http://portal.te.gob.mx/colecciones/sentencias/html/SUP/2004/JDC/SUP-JDC-00041-2004. htm, consultada el 21 de septiembre de 2012. 
juicio, debe cumplir para ser considerado como un mecanismo viable para recabar el voto ciudadano. Tal es el caso de Julio Téllez Valdés, quien haciendo un estudio minucioso sobre la doctrina del tema, arguye que entre esos atributos deben encontrarse, necesariamente, los siguientes: auténtico, accesible, anónimo, auditable, comprobable, código abierto, de costo reducido, confiable, robusto, compatible, comprensible, de fácil uso, fiable, veraz, imposible de ser objeto de coacción, imparcialidad, movilidad, neutralidad, voto rápido y unicidad. ${ }^{7}$

Atributos todos que, en suma, se traducen en mayor certeza, legalidad y, como ya se analizó, transparencia. El ciudadano debe contar con plenas garantías de que la elección se desarrolla con estricto apego a la Constitución y las leyes, así como en cabal observancia de los principios rectores del ejercicio de la función electoral del país.

Por lo que se refiere a las modalidades bajo las cuales se puede implementar el voto electrónico, ya se ha señalado con anterioridad que esta manera de ejercer el derecho al sufragio tiene el rasgo distintivo de hacer uso de dispositivos y recursos tecnológicos, a diferencia de la votación tradicional que consiste en que el elector acude a una casilla, en la que se le entrega una boleta de papel en la que el ciudadano marcará la opción de su preferencia y la depositará en la urna correspondiente para que, con posterioridad, la autoridad proceda al escrutinio y cómputo respectivos.

De acuerdo a lo anterior, se advierte que la doctrina especializada e, incluso, resoluciones jurisdiccionales distinguen, en primera instancia, entre votación electrónica presencial y remota, para referirse a si el voto se emite en un centro de votación o casilla o bien, desde un lugar diverso. Ya sea el voto electrónico presencial o remoto, existen varias modalidades para que se emita. ${ }^{8}$

7 Cfr. Téllez Valdés, Julio, El voto electrónico, Temas selectos de Derecho Electoral, núm. 14, México, Tribunal Electoral del Poder Judicial de la Federación, 2010, pp. 19 y ss.

8 A mayor abundamiento, es ilustrativa la exposición planteada respecto de este tema en el portal electrónico de ACE Project, http://aceproject.org/ace-es/topics/va/vai/onePage, consultada el 21 de septiembre de 2012. De igual manera, resulta orientador el criterio sustentado por la Sala Superior del Tribunal Electoral del Poder Judicial de la Federación al dictar sentencia en el expediente identificado con la clave SUP-JRC-306/2011, mediante la cual se avaló el sistema electrónico por Internet como mecanismo válido para recabar el voto de los ciudadanos del Distrito Federal residentes en el extranjero para elegir jefe de gobierno en el proceso electoral ordinario 2011-2012 (http://www.te.gob. $m x /$ Informacion_juridiccional/sesion_publica/ejecutoria/sentencias/SUP-JRC-0306-2011. $p d f)$, consultada el 21 de septiembre de 2012. 
Por lo que se refiere a la modalidad presencial, el mecanismo por excelencia es el de la urna electrónica, que consiste en un aparato en el que, a través de una pantalla, el ciudadano puede observar las distintas opciones para que elija la de su preferencia, ya sea en la propia pantalla o a través de un teclado para tal fin. Una vez que el ciudadano ha marcado la opción de su preferencia, se imprime un comprobante, mismo que queda resguardado en la propia urna para efectos de cotejo y comprobación al momento del escrutinio y cómputo. Es claro que las características o especificaciones del aparato pueden variar, de acuerdo a las necesidades o requerimientos señalados por la autoridad administrativa electoral. En todo caso, es importante señalar que dicho aparato debe salvaguardar y garantizar la secrecía del voto.

En cuanto a la modalidad remota, existen diversos mecanismos que podrían analizarse en cuanto a su idoneidad para permitir el ejercicio del voto con total secrecía y seguridad. Tal es el caso de la red mundial de información Internet; la telefonía celular o fija; así como la mensajería instantánea.

Por lo que se refiere a la Internet, ésta puede permitir a los ciudadanos votar desde cualquier lugar del país o del mundo para la elección de que se trate, con seguridad y secrecía. Se trata de una opción relevante, considerando la permeabilidad que esta red ha alcanzado en el país así como su fácil uso. No pasa desapercibido que, de acuerdo con la Asociación Mexicana de Internet, para fines de 2011 se contaba con un total de 40.6 millones de usuarios, lo que representó un incremento de $14 \%$ respecto del ejercicio anterior, en el que se tuvo registro de 34.9 millones de internautas. ${ }^{9}$ Si bien es cierto que el número de usuarios sigue siendo bajo respecto del que se observa para otros países, así como en términos comparativos respecto de la población nacional, es inconcuso que se trata de un medio de comunicación dinámico y en constante desarrollo.

Otro de los mecanismos electrónicos a través de los cuales se puede ejercer el voto de manera remota es la telefonía celular o fija. La cobertura que alcanzan las redes de esta modalidad de comunicación permiten alcanzar zonas remotas, aunado al hecho de que el uso de este tipo de dispositivos es sencillo y asequible a la población. De hecho,

9 Asociación Mexicana de Internet (AMIPCI), Hábitos de los usuarios de Internet en México 2012, http://www.amipci.org. $m x /$ ?P=editomultimediafile\&Multimedia=115\&Typ $e=1$, consultada el 21 de septiembre de 2012 . 
de acuerdo con la Comisión Federal de Telecomunicaciones, mientras que en 1990 había registro de 63900 líneas celulares, para finales de 2011 se registró un total de 94565305 líneas del mismo tipo. Por lo que se refiere a la telefonía fija, si bien el incremento en el número de registros no ha sido tan significativo como en el caso de la telefonía móvil, no pasa desapercibido que mientras que en 1990 se tenían 5352824 , para fines de 2011 se contaba con un total de $19731369 .{ }^{10}$ En todo caso, ambas modalidades dan cuenta del grado de permeabilidad que las mismas han alcanzado en el país en los últimos años y las razones por las que, de considerarse pertinente, podrían ser una opción seria como método para recabar la votación de los ciudadanos en los procesos electorales.

En el caso de la mensajería instantánea, y toda vez que ésta se emite a través de equipos de telefonía celular, resultan aplicables las características y datos referidos en el párrafo precedente. En todo caso, resulta importante destacar el grado de permeabilidad que entre la población han alcanzado estos dispositivos de intercomunicación entre la población mexicana y, para el caso que nos ocupa, ya sea una secuencia numérica o un mensaje de texto, es indiscutible que la telefonía podría perfilarse como medio para recabar la votación en los procesos electorales, previo análisis de viabilidad jurídica y técnica.

\section{Experiencia internacional en materia de voto electrónico}

Una vez que se ha analizado el concepto, las características y las modalidades que reviste el voto electrónico, es oportuno analizar cuál ha sido la experiencia internacional en el tema. Qué países lo han implementado y para qué tipos de elección.

Lo anterior es relevante, si no se pierde de vista que hablando de problemas de carácter público, la perspectiva comparada resulta útil e ilustrativa para conocer el impacto que determinada reforma, acción gubernamental o programa de gobierno puede tener en un lugar y contexto determinados. Es claro que un programa que resultó exitoso

10 Portal de la Comisión Federal de Telecomunicaciones en Internet http://siemt.cft. gob.mx/SIEM/, consultado el 21 de septiembre de 2012. 
en un lugar no puede adoptarse de manera mecánica en otro distinto sin que antes haya habido un análisis de factibilidad, así como un estudio de las circunstancias, el contexto y la situación o problema concreto que se pretende atender.

Así, no es casual que los estudiosos y doctrinarios de los procesos de diseño, elaboración e implementación de políticas públicas, orienten sus estudios sobre los procesos de elaboración y reformas de políticas públicas en distintos países, desde dos perspectivas esencialmente: por una parte, por qué en países semejantes en términos institucionales adoptan estrategias de política pública diferentes; por otro lado, por qué países heterogéneos en términos de desarrollo político adoptan políticas públicas semejantes y cuáles son los factores que explican que una misma política, arroje resultados distintos. ${ }^{11}$

En cuanto al ámbito internacional, es notorio que el voto electrónico ha venido adquiriendo gran relevancia en muchos países del mundo, pues un número creciente lo ha venido implementando para la celebración de sus procesos electorales. Tal es el caso de países como Estonia, Francia, los Países Bajos, algunos estados en la Unión Americana, Canadá, España, Suiza y Austria, que han recurrido a esta forma de votación por la cual el electorado puede sufragar por medio de un asistente digital como lo es la urna electrónica, o bien, a través de cualquier instrumento que cuente con conexión a Internet. Es decir, voto electrónico presencial o remoto, según se expuso con anterioridad. ${ }^{12}$

Igualmente relevantes resultan los casos de Brasil, India y Venezuela, que han implementado sistemas de votación electrónica con resultados exitosos, a pesar de tratarse de países en vías de desarrollo. ${ }^{13}$

Por lo que se refiere a Latinoamérica, resulta interesante el hecho de que la gran mayoría de leyes electorales de los países del continente prevean el uso de boletas de papel para la celebración de sus elecciones; sin embargo, existen casos en los que no se excluye el uso de otros

${ }^{11}$ Cfr. Przeworski, Adam y Teune, Henry, The Logic of Comparative Social Inquiry, Nueva York, Wiley-Interscience, 1970, pp. 31 y ss.

12 Instituto Electoral del Distrito Federal, Acuerdo del Consejo General del Instituto Electoral del Distrito Federal por el que se podrán determinar dos modalidades para recabar el voto de los ciudadanos del Distrito Federal residentes en el extranjero para elegir al Jefe de Gobierno en el Proceso Electoral Ordinario 2011-2012, ACU-047-11 (http:// www.iedf.org.mx/taip/cg/acu/2011/ACU-047-11.pdf), consultada el 21 de septiembre de 2012.

13 Cfr. Téllez, op. cit., p. 30. 
mecanismos para recabar la votación e, incluso, existen casos, como en Costa Rica, en los que se prevé expresamente el uso de dispositivos electrónicos para el ejercicio del sufragio.

A manera de ejemplo, siguiendo la exposición que al respecto plantea Fernando Tuesta, en el caso ecuatoriano, la legislación hace referencia al uso expreso de papeletas, pero no es excluyente en cuanto al uso de otros procedimientos de votación, escrutinio o cualquier mecanismo automatizado. La legislación argentina menciona expresamente el uso de boletas electorales, pero no excluye otros procedimientos de voto, escrutinio o cualquier mecanismo automatizado. La legislación paraguaya indica tamaños, formas y colores de las boletas y tiempos al momento de la votación; sin embargo, al no estar prohibido expresamente el voto electrónico, implícitamente permite que éste se aplique. En el caso peruano, la ley determina la forma y los formatos del material electoral y hace hincapié, precisamente, en todos aquellos elementos que con una propuesta de voto electrónico desaparecerían y, consecuentemente, significarían un ahorro de tiempo y recursos (formatos, copiado de actas, etcétera). Por su parte, en Puerto Rico, la ley de la materia indica que para cada elección, cualquiera que sea su naturaleza, la Comisión Estatal de Elecciones debe determinar la forma de votación, con lo que deja abierta la posibilidad a la incorporación de nuevas tecnologías para el ejercicio del voto por parte de los ciudadanos. En Uruguay, finalmente, la legislación señala exhaustivamente las etapas para emitir el voto con sobre de votación, pero no prohíbe o restringe que se puedan utilizar otros mecanismos para emitir y recabar los sufragios y, posteriormente, realizar el escrutinio y cómputo respectivos. ${ }^{14}$

Como se puede advertir, en todo caso, las nuevas TIC's cada vez se utilizan con mayor frecuencia para la organización y el desarrollo de los procesos electorales, y cada vez son más países los que se suman a su uso y aprovechamiento, no sólo por su accesibilidad y su fácil manejo, sino por la reducción significativa de costos que puede conllevar y la obtención de resultados altamente confiables, muy poco tiempo después de que concluyó la jornada electoral respectiva.

Si como se ha analizado, la experiencia internacional parece demostrar que el alto grado de viabilidad y confiabilidad del uso de las TIC's aplicadas a los procesos electorales ha resultado fructífera, a

14 Cfr. Tuesta, op. cit., pp. 965 y ss. 
grado tal incluso que los marcos normativos se han venido adecuando para prever su uso y aprovechamiento de manera expresa, se considera oportuno analizar cuál ha sido la experiencia de nuestro país en el tema para, posteriormente, determinar si un proyecto de esta trascendencia puede resultar viable y conveniente para el país, en sus circunstancias actuales, dadas las ventajas y desventajas que el mismo puede conllevar.

\section{Experiencia mexicana en materia de voto electrónico}

La experiencia que México ha tenido en materia de implementación del voto electrónico ha sido dinámica en los últimos años y ha abarcado el voto electrónico presencial, a través de un dispositivo o urna en una casilla electoral, hasta la modalidad remota, a través de Internet $\mathrm{u}$ otro mecanismo como los que fueron descritos en el apartado I de este texto. Como se refirió con anterioridad, entre las razones que han motivado el debate sobre la pertinencia de la implementación del voto electrónico se encuentran, por una parte, la reducción de costos y tiempos de los procesos electorales, específicamente en lo concerniente a recabar la votación y llevar a cabo el escrutinio y cómputo respectivos; por otra parte, se analiza la forma de aplicar las nuevas TIC's para fomentar mayor participación y facilitar el ejercicio del derecho del voto, al permitir que se pueda sufragar desde cualquier lugar con acceso a una red de telecomunicaciones.

Ahora bien, por lo que se refiere al voto electrónico presencial que, como ya se analizó, consiste en el uso de un dispositivo a través del cual el votante elige la opción de su preferencia, algunas de las entidades federativas han hecho uso de urnas electrónicas con efectos vinculantes, para recabar la votación. Tal es el caso de Coahuila que, a decir de Julio Téllez:

Es la entidad federativa más avanzada en el ámbito de voto electrónico, ya que en esta entidad se han utilizado de manera gradual en varios de sus distritos electorales locales urnas electrónicas con efectos vinculantes, en sus elecciones estatales de 2005, 2008... y 2009, con resultados muy positivos y aportando una gran experiencia en materia de comicios electrónicos. ${ }^{15}$

15 Téllez, op. cit., p. 30 
El Distrito Federal es otra de las entidades que han utilizado exitosamente urnas electrónicas con efectos vinculantes para recabar la votación. Al respecto, es de destacar que:

Desde el año 2000, el IEDF se ha dado a la tarea de investigar y desarrollar nuevos instrumentos tecnológicos que permitan la modernización, automatización y reducción de costos de los procesos electorales y de participación ciudadana, entre estos se destacan: las urnas electrónicas, los escáneres de reconocimiento óptico y los lectores de código de barra. ${ }^{16}$

Por lo que se refiere a la urna electrónica propiamente dicha, no debe perderse de vista que el Instituto Electoral del Distrito Federal adquirió prototipos de urna electrónica semiindustrial para evaluar su funcionamiento y, de ser el caso, introducir estos dispositivos tecnológicos como medios para recabar la votación en los procesos electorales con efectos vinculantes. En efecto, luego de diversas evaluaciones, consistentes en ejercicios de práctica, así como elecciones con efectos vinculantes de diversa naturaleza, incluyendo procesos internos de partidos políticos y consultas ciudadanas, el Consejo General del Instituto Electoral local determinó utilizar urnas electrónicas en 40 casillas electorales, ubicadas en cada uno de los distritos electorales uninominales en los que se divide el territorio del Distrito Federal, cuyos resultados tuvieron efectos vinculantes y los votos obtenidos por esa vía fueron igualmente contabilizados que aquéllos que fueron emitidos de manera tradicional, a través de una boleta de papel.

Así, el 29 de abril de 2009, el Consejo General del Instituto Electoral del Distrito Federal aprobó el Acuerdo por el que se aprueba la utilización de urnas electrónicas para la recepción y cómputo de votos en el proceso electoral local ordinario 2008-2009, en el cual se razona, por una parte, que los artículos 213 y 214 del otrora Código Electoral del Distrito Federal determinaban que el Instituto Electoral podría hacer uso de sistemas electrónicos de votación en los procesos electorales y de participación ciudadana, los cuales debían garantizar la efectividad y autenticidad del sufragio, así como las características que debían cumplir los sistemas para el ejercicio del voto bajo esta modalidad,

16 Portal electrónico del Instituto Electoral del Distrito Federal, http://www.iedf.org. $m x /$ index.php/elecciones/innovaciones-tecnologicas-electorales, consultada el 21 de septiembre de 2012 . 
particularmente los programas informáticos que se utilizaran para la recepción y cómputo de los votos. Asimismo, el Acuerdo de mérito determina que los ejercicios practicados permitieron comprobar la viabilidad técnica para utilizar las urnas electrónicas en ejercicios vinculantes, por lo que se procedió a realizar diversas presentaciones de dichas urnas electrónicas. Tal es el caso de las presentaciones celebradas ante las Comisiones de Participación Ciudadana y de Asuntos Político Electorales, ambas de la Asamblea Legislativa, así como las celebradas ante diversos partidos políticos y representantes de los medios de comunicación. ${ }^{17}$

Ahora bien, toda vez que los resultados obtenidos fueron considerados como muy positivos, tanto por la autoridad electoral como por los partidos políticos y los ciudadanos, e incluso, los resultados de la votación obtenida a través de urnas electrónicas no fue impugnada, esto es, todas las fuerzas políticas aceptaron los resultados de la votación emitida a través de dichos dispositivos, el Instituto se abocó al análisis sobre la pertinencia o viabilidad de introducir paulatinamente este tipo de dispositivos como medio para recabar la votación en los procesos electorales y de participación ciudadana, hasta lograr la cobertura en todas las casillas que se llegaran a instalar. Se determinó que para la elección de 2012 se contaría con al menos 1000 urnas electrónicas para recabar la votación. Si bien esto no ocurrió derivado de cuestiones administrativas, no significa que el proyecto se haya cancelado o que haya sido infructuoso, más bien pone de manifiesto que, al tratarse de uno de los proyectos de mayor envergadura que ha emprendido el Instituto Electoral local y de todas las implicaciones que el mismo puede producir en el sistema político electoral de la ciudad, ameritan ser analizados en todos sus aspectos, incluso los mínimos, para garantizar que los mismos, al implementarse, resulten exitosos y arrojen los resultados esperados no sólo por las autoridades, sino por los ciudadanos. En suma, no se debe correr el riesgo de que, por hacer uso de las TIC's, se comprometan o pongan en entredicho los principios y valores que sustentan el ejercicio de la función electoral y, principalmente, el derecho ciudadano al sufragio.

${ }_{17}$ Instituto Electoral del Distrito Federal, Acuerdo del Consejo General del Instituto Electoral del Distrito Federal, por el que se aprueba la utilización de urnas electrónicas para la recepción y cómputo de votos en el proceso electoral local ordinario 2008-2009, ACU-419-09 del 29 de abril de 2009 (http://www.iedf.org.mx/taip/cg/acu/2009/ACU419-09.pdf) consultada el 21 de septiembre de 2012. 
En este sentido, no debe descartarse el hecho de que, en breve, el proyecto pueda implementarse y devenga como un mecanismo eficiente para recabar la votación hasta lograr la cobertura total en la ciudad y que, en lo sucesivo, esta sea la manera de ejercer el derecho al voto, máxime si no se pierde de vista el hecho de que, a la fecha, el Instituto Electoral del Distrito Federal es titular de los derechos sobre la urna electrónica que ha utilizado.

Otro caso exitoso sobre el uso de urnas electrónicas para recabar la votación a través de dispositivos electrónicos es el relativo al municipio de Tuxcueca, Jalisco, en 2009. El Instituto Electoral y de Participación Ciudadana de la entidad determinó el uso de estos dispositivos para la celebración de la jornada electoral extraordinaria suscitada con motivo del empate de votación entre los partidos políticos Acción Nacional y Revolucionario Institucional. En dicha elección se utilizaron 10 urnas electrónicas y se registró una participación ciudadana de $59.9 \%$.

Si bien el uso de urnas electrónicas no ha logrado la permeabilidad, difusión y cobertura que se esperarían en términos de modificar la manera en que se recaba la votación para los distintos procesos electorales que se llevan a cabo en el país en los distintos ámbitos de gobierno, es incuestionable que los ejercicios que se han realizado ponen de manifiesto no sólo que se trata de dispositivos que garantizan total confiabilidad en el manejo de los votos - recepción, escrutinio y cómputo-, sino que se trata de un mecanismo que, eventualmente y una vez adecuado el marco normativo atinente, se estaría perfilando como una nueva manera de recabar la votación en los procesos electorales de todo el país, transformando la vía tradicional de votación y todo lo que la misma conlleva, en términos logísticos.

En efecto, entre los aspectos positivos que los estudiosos del tema reconocen en la implementación de la urna electrónica como medio para recabar la votación, se encuentra que permitirían reducir en gran medida los costos que se generan en la organización de la elección, fabricación de materiales y documentación, capacitación de integrantes de mesas directivas de casilla, aunado al hecho de que permitiría a los ciudadanos conocer los resultados de la elección muy poco tiempo después de concluida la jornada electoral, lo que reduciría de manera relevante los errores suscitados con motivo del llenado de actas y el escrutinio y cómputo, situación que, por ende, se traduciría en una reducción sensible en el número de impugnaciones por este tipo de irregularidades. 
Quienes se oponen a la implementación de las urnas electrónicas como mecanismo de votación arguyen que se trata de equipos costosos y que no garantizan absoluta secrecía y confiabilidad del voto. Al respecto, no debe perderse de vista el hecho de que si bien la adquisición de los equipos supondría una fuerte inversión inicial, se trata de un gasto que no volvería a ejercerse durante toda la vida útil de esos equipos, reduciendo dichos gastos al mantenimiento de los equipos, situación que, en términos comparativos, es sustancialmente inferior a los gastos que se originan por la fabricación de materiales electorales, documentación electoral, capacitación ciudadana, entre otros.

Sólo en el caso del Distrito Federal, en el periodo comprendido entre 2006 y 2012, se han dejado de destinar más de 80 millones de pesos para la fabricación de material y documentación electoral, por la rehabilitación de materiales y equipos. En suma, en los tres procesos electorales que ha organizado la actual administración del Instituto Electoral del Distrito Federal, la determinación de adoptar medidas de racionalidad y austeridad en el uso de recursos, específicamente a través de la reutilización de materiales electorales generó que \$81 203953.75 se dejaran de destinar a ese rubro, pudiendo ser aplicados en otros conceptos, reduciendo así, algunos de los costos inherentes a la organización y desarrollo de los procesos electorales. Por el contrario, si el Instituto Electoral local no hubiera optado por la reutilización de materiales y, en cambio, hubiera decidido adquirirlos nuevos, habría erogado más de 100 millones de pesos para cubrir a cabalidad las necesidades en materia de organización electoral en los procesos electorales correspondientes a 2006, 2009 y 2012. ${ }^{18}$ Si un cálculo semejante se lleva a cabo para cada una de las entidades federativas y para el ámbito federal, es inconcuso que el resultado será una cifra cuantiosa que, de llegar a implementarse un sistema de votación distinto al actual, se dejaría de destinar a esos fines y esos recursos podrían asignarse a otras necesidades del país.

Por lo que se refiere al voto electrónico en su modalidad remota, es de señalar que en el ámbito federal no existe precedente alguno de procesos electorales que se hayan desarrollado de esta manera; sin

$18 C f r$. Humphrey Jordan, Carla A., "Rehabilitación, conservación y reutilización de materiales electorales y su impacto presupuestal en el DF", en La silla rota, 26 de julio de 2012 (http://www.lasillarota.com/index.php?option=com_k2\&view=item \&id $=46008$ :rehabilitación-conservación-y-reutilización-de-materials-electorales-y-su-impacto-presu puestal-en-el-df\&Itemid=186), consultada el 21 de septiembre de 2012. 
embargo, por lo que se refiere a las entidades federativas, el Distrito Federal implementó de manera exitosa del voto electrónico a través de Internet y, de hecho, esta circunstancia colocó en el debate público el tema sobre la viabilidad o pertinencia material y jurídica de adoptar este sistema de votación en todas las elecciones del país e, incluso, las que se organizan para recabar el voto de los ciudadanos que radican fuera del territorio nacional. Para comprender de mejor forma esta propuesta, es oportuno hacer un recuento del contexto en que surgió la misma y sus características.

En primera instancia, es importante recordar que el pasado 1o. de julio los ciudadanos del Distrito Federal residentes en el extranjero pudieron emitir, por primera vez, su voto para elegir jefe de gobierno del Distrito Federal y que, a diferencia de lo que ocurre para el caso de presidente de la República, en el que la ley establece expresamente que la votación será a través de correo ordinario, en el ámbito local la ley permite que se exploren otras vías o mecanismos, incluidos los electrónicos.

Como es del conocimiento general, la regulación e implementación del voto de los mexicanos residentes en el extranjero fue producto de importantes esfuerzos y coordinación entre el Congreso de la Unión, el Instituto Federal Electoral, así como de diversas organizaciones ciudadanas que durante mucho tiempo habían pugnado por la materialización de este derecho previsto constitucionalmente y que se materializaron en el decreto de reformas al Código Federal de Instituciones y Procedimientos Electorales publicado en el Diario Oficial de la Federación el 30 de junio de 2005.

En congruencia con la regulación e implementación del voto de los mexicanos en el extranjero para la elección de presidente de la República que se llevó a cabo por primera vez en la historia nacional en 2006. En el ámbito del Distrito Federal también se han llevado a cabo acciones para la instrumentación y materialización de este importante derecho.

De esta manera, en 2010 el legislador local determinó reconocer y garantizar el derecho de voto para la elección de jefe de gobierno de los ciudadanos del Distrito Federal residentes en el extranjero, por lo que a partir de la aprobación del nuevo ordenamiento, el Instituto Electoral del Distrito Federal, en su calidad de autoridad electoral en el Distrito Federal a cuyo cargo se encuentra la organización de los procesos electorales locales, ha concentrado sus esfuerzos en adoptar 
las medidas y acciones tendientes a dar cumplimiento a las disposiciones del Código de la materia en este tema, entre las que destaca la celebración de convenios de apoyo y colaboración con otras instituciones y dependencias para conocer el número de ciudadanos del Distrito Federal residentes en el extranjero; la integración de la Lista Nominal respectiva; entre otras.

Lo anterior resulta relevante, porque de manera inédita en la historia de todo el país, el Instituto Electoral determinó utilizar, además de la vía postal, el voto electrónico por Internet para recabar los votos de los ciudadanos del Distrito Federal residentes en el extranjero para la elección de jefe de gobierno. ${ }^{19}$ Es importante destacar en este punto, que algunos partidos políticos consideraron que esta acción violentaba el sistema electoral del país, pues se estaba creando una forma de emitir el voto distinta a la prevista por la ley. Si bien el órgano jurisdiccional local dio la razón a los recurrentes y determinó revocar el Acuerdo respectivo por considerar que el voto electrónico a través de Internet no garantizaba plena secrecía y, por ende, podría comprometer las características inherentes al sufragio, consideración distinta tuvo la Sala Superior del Tribunal Electoral del Poder Judicial de la Federación, que consideró que se trataba de un avance significativo en el régimen democrático del Distrito Federal y del país, y que en nada violentaba el marco normativo electoral, en lo relativo a la forma de emitir y recabar el voto, pues de la revisión del procedimiento se advertía que existían condiciones suficientes para garantizar que el voto se emitiera en condiciones de seguridad, confiabilidad y secrecía. ${ }^{20}$

Ahora bien, entre las acciones emprendidas por el Instituto Electoral local para la organización de la elección desde el extranjero en cualquiera de las dos modalidades aprobadas, postal y electrónica a través de Internet, se sostuvieron reuniones de trabajo con diversas

19 Instituto Electoral del Distrito Federal, Acuerdo del Consejo General del Instituto Electoral del Distrito Federal por el que se aprueban los mecanismos para recabar el voto de los ciudadanos del Distrito Federal residentes en el extranjero para elegir al jefe de gobierno en el proceso electoral ordinario 2011-2012, ACU-069-11, 31 de octubre de 2011, (http://www.iedf.org.mx/taip/cg/acu/2011/ACU-069-11.pdf), consultada el 21 de septiembre de 2012.

20 A mayor abundamiento, resulta ilustrativa la lectura de la sentencia dictada por la Sala Superior del Tribunal Electoral del Poder Judicial de la Federación en el expediente SUP-JRC-306/2011, del 12 de enero de 2012 (http://www.te.gob.mx/Informacion_juridiccional/sesion_publica/ejecutoria/sentencias/SUP-JRC-0306-2011.pdf), consultada el 21 de septiembre de 2012 . 
autoridades e instancias nacionales y del extranjero, y se suscribieron convenios de apoyo y colaboración para la implementación de esa elección.

Es importante señalar que como parte de los trabajos realizados con esas instituciones se encuentra, entre otras, la determinación del número de ciudadanos del Distrito Federal residentes en el extranjero posibles votantes y sus lugares de localización. Así, de acuerdo con la información que entonces proporcionó el Instituto de los Mexicanos en el Exterior, hasta 2009 había un total de 93,262 ciudadanos del Distrito Federal residentes en el extranjero, distribuidos por continentes, de la siguiente manera:

\section{Cuadro 1}

Ciudadanos del Distrito Federal residentes en el extranjero (2009)

\begin{tabular}{|c|c|c|}
\hline Continente & $\begin{array}{c}\text { Ciudadanos del Distrito } \\
\text { Federal residentes en el } \\
\text { extranjero }\end{array}$ & Porcentaje \\
\hline África & 87 & 0.09 \\
\hline América & 87113 & 93.41 \\
\hline Asia & 1221 & 1.31 \\
\hline Europa & 4680 & 5.02 \\
\hline Oceanía & 161 & 0.17 \\
\hline TOTAL & $\mathbf{9 3 2 6 2}$ & $\mathbf{1 0 0 . 0 0}$ \\
\hline
\end{tabular}

Asimismo, de acuerdo con la misma institución, las entidades federativas con mayor índice de migración son el Distrito Federal, Chihuahua, Veracruz, Jalisco, Puebla, Nuevo León, Estado de México, Guanajuato, Michoacán y Tamaulipas, lo cual se confirma si se considera que, en la elección de mexicanos residentes en el extranjero para presidente de la República que se llevó a cabo en 2006, los mexicanos que más votaron fueron los ciudadanos del Distrito Federal al acumular 5402 votos, es decir $16.5 \%$ del total recibido, que fue de $32632 .{ }^{21}$

No pasa desapercibido, por otra parte, que otras instituciones, como la Secretaría de Desarrollo Rural y Equidad para las Comunidades del Gobierno del Distrito Federal reportaron un número aproximado de

${ }^{21}$ Cfr. Humphrey J., Carla A., "Voto de los ciudadanos del Distrito Federal residentes en el extranjero", Justicia Electoral, cuarta época, vol. 1, núm. 8, 2011, pp. 297 y ss. (http:// portal.te.gob.mx/sites/default/files/publicaciones/doc-relacionado/juel_4a_e_n8_2.pdf), consultada el 21 de septiembre de 2012. 
755200 ciudadanos del Distrito Federal residentes en el extranjero, particularmente los Estados Unidos de América y Canadá. ${ }^{22}$

Es importante señalar que la diferencia en los datos que reportan ambas instituciones deriva de la fuente de su información, ya que mientras que para el Instituto de los Mexicanos en el Exterior la fuente de sus datos es el número de ciudadanos que han solicitado su cédula consular, la cual es de tramitación opcional, en el caso de la Secretaría de Desarrollo Rural y Equidad para las Comunidades del Gobierno del Distrito Federal, ésta obtiene los datos a partir de las encuestas a los habitantes del Distrito Federal que ha venido practicando anualmente, desde 2008. En el caso específico de la cifra indicada con anterioridad, ésta deriva de las encuestas practicadas en 2008 y 2009, de conformidad con el Cuarto Informe de Labores de 2010 de la propia Secretaría. ${ }^{23}$

Aunado a lo anterior, no pasa desapercibido que parte de la problemática que representa la sistematización de la información consiste en que los ciudadanos del Distrito Federal residentes en el extranjero no se encuentran concentrados o agrupados en sitios específicos, como ocurre con los ciudadanos de otras entidades federativas, lo que genera que se cuente con datos diferenciados en cuanto a su número y ubicación. De ahí que ese sea precisamente uno de los retos de la autoridad electoral local para organizar esa elección. ${ }^{24}$

Todo esto resulta relevante, porque una vez determinado el universo de posibles votantes, se determinaron las estrategias de difusión que se consideraron atinentes para fomentar el registro de los ciudadanos a la Lista Nominal respectiva y que optara por cualquiera de las dos modalidades aprobadas.

Al respecto, es importante señalar que del total de 10782 ciudadanos que solicitaron su registro a la Lista Nominal de Electores del Distrito Federal residentes en el Extranjero, 6592, equivalentes a 61\% optaron por la modalidad postal, mientras que 4190 ciudadanos (39\%) decidieron emitir su voto vía electrónica.

Lo anterior es relevante, no sólo porque la ciudadanía del Distrito Federal residente en el extranjero ha demostrado gran entusiasmo en el ejercicio de sus derechos político electorales a través de una participación importante en el proceso electoral; además, porque es la pri-

${ }_{22}$ Idem.
${ }_{23}$ Idem.
${ }_{24}$ Idem. 
mera vez en el país, que se utiliza un mecanismo electrónico remoto para emitir y recabar la votación y porque, de esta manera, el Instituto Electoral del Distrito Federal se coloca a la vanguardia en la organización de procesos electorales, poniendo de manifiesto la necesaria interrelación de los procesos electorales y las nuevas TIC's.

Lo señalado en los párrafos precedentes se corrobora al verificar los resultados electorales obtenidos: de los 6592 ciudadanos del Distrito Federal residentes en el extranjero que optaron por la vía postal para emitir su sufragio, votaron un total de 5276, es decir, $80.03 \%$, mientras que en el caso del voto electrónico por Internet, de los 4190 ciudadanos que optaron por esta modalidad, votaron 2639, lo que corresponde a un $62.98 \%$. En función de los registros recibidos y la votación emitida por cada uno, los países con mayor participación son: España con el $80.1 \%$, Canadá 77.9\%, Alemania 75.7\%, Francia $74.80 \%$, Reino Unido 74.8\%, y Estados Unidos 70.7\%. ${ }^{25}$ Asimismo, proporcionalmente países europeos como Reino Unido, Alemania, España y Francia votaron más por Internet que países del continente americano como Estados Unidos de América o Canadá, tal como se muestra en el siguiente cuadro:

- Postal \% $\square$ Internet $\%$

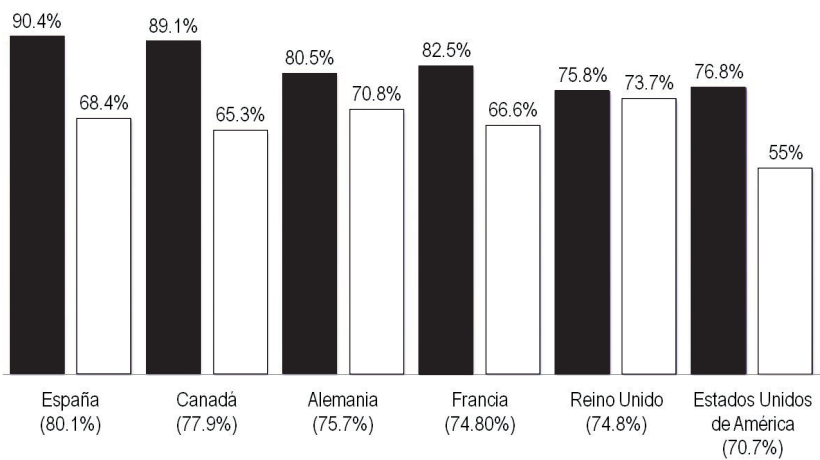

Fuente: Elaboración propia con datos del Instituto Electoral del Distrito Federal. ${ }^{26}$

25 México, Instituto Electoral del Distrito Federal, "Presenta consejera electoral, ponencia sobre el voto de los chilangos desde el extranjero", Instituto Federal Electoral 15 de octubre de 2012. (http://www.iedf.org.mx/index.php/component/blog_calendar/?year= 2012\&month=10\&day=15\&modid=103) consultada el 29 de octubre de 2012.

26 Los porcentajes están calculados en relación al número de ciudadanos que se inscribieron para votar desde el extranjero por jefe de gobierno y la vía por la que optaron hacerlo. 
Es importante señalar que dicha votación no fue impugnada, por lo que adquirió el carácter de definitiva y se puso de manifiesto así, la conformidad de las fuerzas políticas, sus candidatos, y la ciudadanía con el uso de este mecanismo para recabar la votación, su funcionamiento y sus resultados.

Así, se ha puesto de manifiesto que el voto electrónico por Internet es una opción altamente confiable para emitir el voto con total seguridad y secrecía, aunado al hecho de que, al tratarse de un medio que permite votar desde cualquier computadora personal, se fomenta la participación ciudadana, pues permite que se vote desde el hogar, el centro de trabajo, la escuela y, en general, desde cualquier lugar con acceso a la red mundial de información. Aunado a lo anterior, los procesos electorales resultan fortalecidos en cuanto a certeza hacia los ciudadanos, candidatos y fuerzas políticas, pues un mecanismo para recabar la votación como éste permite contar con los resultados de manera casi inmediata a la conclusión de la jornada electoral, reduciendo así retrasos en la información, errores humanos en la clasificación de boletas y cómputo de votos y, consecuentemente, una reducción significativa en el número de inconformidades e impugnaciones ante órganos jurisdiccionales.

Además de las ventajas que ofrece el voto electrónico por Internet en cuanto a secrecía y seguridad del voto y las ventajas que ofrece en cuanto al escrutinio y cómputo, no se puede soslayar la importancia que este mecanismo podría adquirir en términos económicos. La implementación de un sistema de votación como el señalado permitiría ahorros significativos en todas las elecciones del país: federales, locales y municipales, pues su implementación sería, por mucho, inferior al costo de la organización de un proceso electoral en la actualidad.

Ahora bien, no pasa desapercibido que los principales críticos a este medio de votación fundan sus argumentos en altos costos, baja seguridad del sistema, así como la inaccesibilidad de Internet a diversos sectores sociales, situaciones que, luego de analizar la elección de jefe de gobierno desde el extranjero en 2012 pierden sentido y que, por el contrario, perfilan este mecanismo como una opción seria y confiable a ser considerada para procesos electorales próximos.

De hecho, no descarto la posibilidad de que, derivado del éxito observado en la elección de jefe de gobierno del Distrito Federal desde el extranjero por esta modalidad, el Congreso de la Unión y las Legislaturas estatales, retomen la experiencia y determinen ajustar los mar- 
cos normativos a que haya lugar para adoptar este mecanismo como medio para recabar la votación no sólo desde el extranjero, sino también desde el territorio nacional, desde cada entidad, cada municipio, cada localidad.

Lo anterior cobra mayor relevancia aún, si no pasa desapercibido que recientemente el Instituto Electoral del Distrito Federal llevó a cabo la Consulta Ciudadana para determinar el uso del presupuesto participativo delegacional correspondiente al ejercicio 2013, en la que los ciudadanos del Distrito Federal pudieron emitir su opinión por Internet de manera segura y sencilla. ${ }^{27}$ Lo que nuevamente pone de manifiesto que la red mundial de información es un mecanismo idóneo y confiable para que los ciudadanos puedan emitir sus votos y opiniones en los procesos electorales y de participación ciudadana.

De modo semejante a lo expuesto respecto del voto electrónico por Internet, ocurriría con la votación que, eventualmente se implementara a través de telefonía móvil o fija, pues es indudable que son medios de comunicación que permiten el manejo de grandes concentraciones de información, que han alcanzado altos índices de penetración social y que propiciarían una mayor participación ciudadana, a bajos costos, en comparación con los costos que se enfrentan hoy en día con la organización de los procesos electorales en todo el país, con la votación tradicional.

De esta manera, el Instituto Electoral del Distrito Federal se ha colocado a la vanguardia y ha dado pasos firmes para el desarrollo democrático de la Ciudad de México y de todo el país, pues el voto electrónico por Internet, si bien se llevó a cabo para el ámbito local, no existe duda de que constituye un referente para todo el país. No obstante, estos logros si bien importantes, representan, a la vez, grandes retos, pues la democracia es dinámica y aún subsisten temas que atender, por lo que autoridades, partidos políticos y ciudadanos deben, hoy más que nunca, sumar esfuerzos orientados a una democracia

27 Del 4 al 8 de noviembre, el Instituto Electoral del Distrito Federal habilitó el sistema de opinión por Internet, en el que participaron 15281 ciudadanos para elegir algunos de los proyectos registrados para sus colonias. Por su parte, 203 ciudadanos más intentaron participar bajo esta modalidad, pero no pudieron hacerlo en virtud de que en sus colonias no hubo proyectos registrados (http://www.iedf.org.mx/index.php/boletines-ycomunicados/456-2012boletines/2245-difunde-iedf-resultados-de-la-participacion-porinternet-de-la-consulta-ciudadana), consultada el 13 de noviembre de 2012. 
efectiva que se traduzca, como lo prevé nuestra Constitución, en un sistema de vida.

\section{V. ¿Es viable la regulación e implementación del voto electrónico en México?}

En los apartados precedentes se han expuesto las modalidades y características del voto electrónico, así como algunas de las principales ventajas y desventajas que podría producir o traer aparejada su implementación en el sistema político electoral mexicano. De la exposición presentada, parece advertirse que el voto electrónico podría resultar viable en México, habida cuenta que permitiría atender dos reclamos o necesidades que, en los últimos años han cobrado auge en el país: por una parte, reducir los costos de los procesos electorales de todo el país, en los distintos ámbitos de gobierno; por otra, buscar mecanismos o procedimientos que permitan lograr una mayor eficiencia y expeditez en cuanto a recabar la votación y llevar a cabo el escrutinio y cómputo respectivos. La implementación del voto electrónico en nuestro país parece una medida que podría contribuir de manera contundente al logro de estos fines, a la atención de estos reclamos sociales, por lo que resulta oportuno reflexionar en torno a la pertinencia y viabilidad de su regulación y posterior implementación y, en ese caso, en los términos en los que debiera emitirse dicha normatividad.

De acuerdo con los teóricos de la elaboración de políticas públicas, para que un asunto sea considerado parte de la agenda pública y, por ende, materia de regulación o atención de las autoridades, es necesario que se trate de:

Circunstancias negativas ya ampliamente aceptadas como tales y que causan abierta inconformidad o insatisfacción entre grupos significativos de la población, quienes reclaman medidas o acciones para su resolución... Aunque en el campo de las políticas públicas existen varias visiones sobre qué es la definición de un problema, en sentido estricto la definición de un problema implica especificar dos elementos centrales: 1 . Una circunstancia; y 2. Los efectos públicos negativos de esa circunstancia. ${ }^{28}$

28 Cfr. Méndez Martínez, José Luis, Formación de la Agenda en Política Pública, Primera Parte, México, Flacso, 2012, pp. 10 y ss. 


\begin{abstract}
A mayor abundamiento, no pasa desapercibido que, de acuerdo con los tratadistas del tema:
\end{abstract}

\begin{abstract}
Por agenda de gobierno suele entenderse en la literatura el conjunto de problemas, demandas, cuestiones, asuntos que los gobernantes han seleccionado y ordenado como objetos de su acción y, más propiamente, como objetos sobre los que han decidido que deben actuar o han considerado que tienen que actuar... En efecto, el que una demanda, problema, cuestión o asunto llegue a ser considerado como punto o tema de la agenda de gobierno, supone analíticamente decisiones antecedentes: la decisión de prestarle atención, la elaboración y selección de su definición, la elaboración y selección de una opción de acción. ${ }^{29}$
\end{abstract}

De acuerdo a lo anterior, se advierte que el tema que nos ocupa satisface los dos supuestos que la doctrina señala como requisitos para ser considerado como problema público y que amerite atención de los órganos públicos. En la especie, la implementación del voto electrónico atendería, por una parte, el reclamo social creciente respecto del alto costo de los procesos electorales y la necesidad de destinar menos recursos para la celebración de comicios y todo lo que ello implica, para que, en su lugar, se destinen a otras necesidades nacionales; por otra parte, el voto electrónico también daría cauce a las preocupaciones manifestadas en cuanto a encontrar procedimientos o mecanismos que fomenten y propicien una mayor participación ciudadana, y que maximicen la eficiencia y la eficacia en el escrutinio y cómputo al dar resultados con mayor celeridad y precisión, reduciendo así inconformidades de partidos políticos y sus candidatos y sus respectivas impugnaciones. Así, es inconcuso que existe un problema o circunstancia que atañe a gran número de ciudadanos y que ese problema o circunstancia está generando efectos negativos hasta en tanto no sea atendido, ya sea por la vía legislativa o alguna otra, a saber, los altos costos de los procesos electorales, la tardanza en conocer los resultados electorales, así como errores humanos de escrutinio y cómputo que generan alto número de inconformidades partidistas y de sus candidatos.

29 Aguilar Villanueva, Luis, “Estudio introductorio”, en Aguilar Villanueva, Luis (ed.), Problemas Públicos y Agenda de gobierno, México, M. A. Porrúa, 1993, p. 29. 
Desde esta óptica, es posible afirmar que si existe convicción sobre los problemas referidos, no debiera existir obstáculo para que el tema forme parte de la agenda pública y sea materia de regulación. No obstante, y como lo demuestra la historia político electoral reciente, si bien se han formulado algunas propuestas legislativas al respecto, éstas no se han concretado en reformas que entren en vigor y que deban implementarse. Tal es el caso, a manera de ejemplo, del Punto de Acuerdo aprobado por la Diputación Permanente de la Asamblea Legislativa del Distrito Federal en sesión celebrada el 8 de junio de 2005, mediante la cual se exhortó a las Cámaras del Congreso de la Unión, legislar en diversos rubros del ámbito electoral, entre ellos, el voto electrónico. ${ }^{30}$ No obstante, es claro que se trata de temas que no se han agotado y que, por el contrario, deben seguir siendo materia de debate y análisis, de manera que el sistema electoral y el régimen democrático del país se encuentre en permanente perfeccionamiento.

Por ello, se insiste en que si al hacer un balance sobre las modalidades que puede revestir el voto electrónico y las ventajas y desventajas que puede traer aparejada su implementación, se advierte que la regulación del tema podría resultar positiva, lo procedente es analizar qué elementos debiera atender una eventual reforma al respecto o en qué términos debiera emitirse:

a) El primer rubro a atender en el tema, es la modalidad. Si se parte del supuesto de que es viable la implementación del voto electrónico, debe precisarse puntualmente la modalidad bajo la cual habrá de implementarse: ya sea presencial, a través de urnas electrónicas o bien, remota a través de Internet o vía telefónica.

b) De acuerdo a las ventajas y desventajas expuestas en el apartado anterior se considera que el voto electrónico por Internet podría tener más efectos positivos que a través de una urna electrónica, no sólo porque la implementación del sistema podría resultar menos onerosa en términos económicos sino porque, al permitir ejercer el voto desde cualquier lugar del mundo con acceso a la red mundial de información, permitiría votar desde el domicilio, centro de trabajo o escolar, lo que también contribuiría a lograr mayor participación ciudadana y que, pensando en el voto de

30 Gaceta Parlamentaria de la Cámara de Diputados del H. Congreso de la Unión, http://gaceta.diputados.gob. $m x /$, consultada el 21 de septiembre de 2012. 
los ciudadanos mexicanos residentes en el extranjero, no sería necesaria una logística alterna, sino que podría aprovecharse el mismo sistema de votación que se implemente para la elección en el territorio nacional.

c) Igualmente, podría optarse por delegar en la autoridad administrativa la determinación del mecanismo para recabar la votación, atento a la evolución y los cambios tecnológicos que ocurren de manera constante. No obstante, en este caso es importante que la atribución se plantee en términos precisos, a efecto de evitar la discrecionalidad, ambigüedad u otros conflictos de interpretación y aplicación normativa.

d) Las medidas de identificación, autenticación y las relativas a la seguridad y cifrado de la información. En efecto, al tratarse de los votos emitidos por los ciudadanos y los efectos que éstos tienen para la integración de los órganos de poder público y de representación popular, es inconcuso que la información debe manejarse con alto grado de secrecía, confidencialidad y seguridad, de manera que el sistema no pueda ser alterado o manipulado ni personas ajenas a la autoridad electoral puedan tener acceso a la misma, con plena transparencia a partidos políticos, candidatos y ciudadanos.

e) En este sentido, la regulación que eventualmente se elaborara debiera establecer qué requisitos habrán de cumplirse o qué información habrá de presentarse para ingresar al sistema, así como medidas básicas o requerimientos técnicos mínimos para garantizar la salvaguarda de la información, estableciendo la posibilidad de que la autoridad administrativa celebre los convenios a que haya lugar con las instituciones, organismos y dependencias que considere necesarios para garantizar el manejo de la información.

f) Ámbito territorial. Si se está pensando en implementar un sistema de votación electrónica a través de Internet que permita recabar la votación en los distintos procesos electorales del país, debiera reflexionarse si habrá de reformarse cada ordenamiento electoral en el país, es decir, el federal y el relativo a cada una de las entidades federativas, estableciendo medidas análogas o semejantes para prever este sistema de votación o bien, sería necesaria una reforma constitucional y, posteriormente, legal, a efecto de implementar un sistema único de votación para todo el país, 
con independencia del proceso electoral de que se trate o la elección que se lleve a cabo.

g) Este rubro reviste la mayor importancia, máxime si no se pierde de vista que el artículo 40 constitucional establece expresamente la voluntad del pueblo mexicano de constituirse en una República representativa, democrática y federal compuesta por estados libres y soberanos en todo lo concerniente a su régimen interior, pero unidos en una federación establecida según los principios de la propia ley fundamental, de lo que se colige que, toda vez que la reforma que se comenta tendría trascendencia en uno de los aspectos del régimen interior de las mismas, debiera estudiarse la pertinencia de que cada estado adecue dicho régimen o bien, sustraer la materia electoral del ámbito local para llegar a un proceso de nacionalización. Se trata, en todo caso, de un tema que amerita un debate nacional por parte de autoridades, fuerzas políticas y, desde luego, ciudadanos.

h) Logística electoral. La reforma que se está planteando tendría repercusiones directas en varias de las etapas de la organización electoral, por lo que será necesario adecuar la legislación para lograr el adecuado funcionamiento del procedimiento implementado. En la especie, se advierte que deberán ser materia de reforma aspectos como la capacitación electoral; el desarrollo de la jornada electoral; el escrutinio y cómputo, entre otros, habida cuenta que estas actividades ya no se realizarían en casilla y, posteriormente, en la sede distrital, sino de manera centralizada; actas y publicación de resultados, así como el sistema de medios de impugnación atinente.

i) En efecto, el sistema electoral vigente está diseñado de acuerdo con la manera tradicional de recabar la votación a través de boletas de papel que se cuentan al término de la jornada electoral, primero en casilla y, posteriormente, en las sedes distritales; el llenado de la documentación respectiva, la forma de impugnar, entre otros. Sin embargo, si este sistema se modifica de manera radical o sustantiva, es inconcuso que se debe proceder en consecuencia, en la legislación y los procedimientos.

Como se puede advertir, el tema que se analiza resulta de la mayor trascendencia para el país, pues no consiste en una mera reforma a la legislación, sino en un procedimiento que permitiría atender re- 
clamos ciudadanos crecientes en los últimos años y que no pueden soslayarse. No obstante, la relevancia del tema es tal, que tampoco puede ser materia de reformas generadas a partir de la premura o estudios superficiales. El país amerita leyes e instituciones acordes a sus circunstancias actuales y que estén a la altura de su sociedad y del momento que se vive en el ámbito y contexto internacionales y que potencialicen la participación ciudadana.

\section{Conclusiones}

En los apartados precedentes se presentó un panorama general respecto del concepto, las características y las modalidades del voto electrónico, así como la experiencia que tanto México como otros países han tenido con el aprovechamiento de las nuevas TIC's para recabar la votación y llevar a cabo el escrutinio y cómputo, en sus procesos electorales. Finalmente, se analizó la pertinencia de que el tema sea regulado en nuestro país y se esbozaron algunos de los aspectos que, se considera, debiera atender cualquier reforma legal que se lleve a cabo en esta materia. De todo ello, es posible concluir lo siguiente:

- El voto electrónico se define como el uso de las nuevas TIC’s para el ejercicio del derecho ciudadano al sufragio.

- El voto electrónico puede revestir diversas modalidades, destacando las siguientes: presencial, a través de una urna electrónica que se instala en una casilla electoral a la que acude el ciudadano, a través de la cual elige la opción de su preferencia; o bien, remota a través de Internet u otros dispositivos, como telefonía móvil o fija o mensajes de texto.

- Son varios los países que han celebrado procesos electorales haciendo uso de TIC's, con gran éxito. En México también han existido diversos ejercicios sobre el ejercicio del voto a través de dispositivos electrónicos e Internet, si bien no en procesos electorales federales, sí en distintas entidades federativas, entre ellas el Distrito Federal.

- Las nuevas TIC's ofrecen un medio para reducir los costos inherentes a la organización de elecciones y una manera de lograr mayor confiabilidad en los resultados electorales, pues arrojan 
información de manera casi inmediata a la conclusión de la jornada electoral, reduciendo los errores humanos, así como las inconformidades e impugnaciones.

- Si bien cada una de las modalidades y mecanismos presenta ventajas y desventajas en su implementación y operación, se considera que las primeras son mayores y que las últimas pierden sustento a partir de los ejercicios previos que se han llevado a cabo y la experiencia internacional en el tema. Aun cuando cualquiera de los mecanismos de voto electrónico supondrían una inversión inicial significativa, ésta es sustancialmente inferior de lo que actualmente se destina para la organización de los procesos electorales.

- Cualquier regulación o reforma que pretenda llevarse a cabo en el tema, debe atender, como mínimo, los siguientes aspectos: la modalidad a adoptar; requisitos de acceso al sistema y medidas de autenticación del elector, así como medidas de seguridad de la información; ámbito territorial de la reforma; adecuaciones a la logística electoral y al sistema de medios de impugnación respectivo.

- Al tratarse de un tema de la mayor relevancia para el país, para su sistema electoral y su régimen democrático, es indiscutible que las reformas deben ser producto de un ejercicio de análisis exhaustivo, pormenorizado y que atienda las necesidades de los involucrados: ciudadanos, partidos políticos, autoridades electorales administrativas y jurisdiccionales, entre otros. 